\title{
COMPORTAMENTO REPRODUTIVO DE VOLATINIA \\ JACARINA JACARINA (LINNAEUS, 1766) EM \\ CATIVEIRO (PASSERES, EMBERIZIDAE)
}

Luiz Octavio Marcondes-Machado

\begin{abstract}
Six pairs of Volatina jacarina have been studied under captivity condition. Territorial defense was displayed by male as well as by female, through agonistic displays joined to characteristic vocalization. Several vocalizations have been identified and described. Courtship behaviour have also been observed. Male and female contributed both to the building of the nest, which is of the cup type, but the male alone was responsible for the chosen place. The average number of eggs by clutch was 2.3 $(n=2.8)$. Incubation have been depending on the sole female and the average incubation period was 10.6 days $(n=10)$. Both male and female fed the young with small arthropods and seeds. Nestlings remained in the nest for nine days $(n=9)$ ). A gular sac was present in the adults while they fed their young. Independence of the young was adquired in about one month. An internuptial plumage appeared during the nonreproductive period.
\end{abstract}

\section{INTRODUÇÃO}

O tisiu, como denominada vulgarmente a espécie Volatinia jacarina (Linnaeus, 1766), é encontrado com bastante freqüência em ambientes abertos onde predominam as gramíneas, áreas cultivadas e terrenos baldios dos bairros periféricos das cidades (Marcondes-Machado, 1976).

Esta espécie tem ampla distribuição geográfica, sendo encontrada desde o sul do México até o norte da Argentina (Pinto, 1944). A subespécie $V$. jacarina encontra-se restrita ao leste e centro do Brasil, Maranhão e Mato Grosso, sul a sudeste do Peru, leste da Bolívia, Paraguai, e norte da Argentina, sul de Mendoza, Córdoba e Buenos Aires, não tendo sido assinalada no Uruguai (Painter \& Storer, 1970).

A subspécie $V . j$. spledens foi estudada em condições naturais tanto por Barnard (1956) e Alderton (1963) no Panamá, como por Carvalho (1957) no Pará (Brasil). Quanto a subespécie $V . j$. jacarina, esta foi muito pouco estudada do ponto de vista de sua biologia e comportamento reprodutivos. Alguns dados sobre ovos e tipo de ninhos podemos encontrar nos trabalhos de Euler (1900) e Von Ihering (1900). 


\section{MATERIAL E MÉTODOS}

No presente estudo foram utilizados 6 casais distribuídos em 1 viveiro de $2,5 \times 2,0 \times 1,0 \mathrm{~m} ; 2$ de $5,0 \times 2,0 \times 1,0 \mathrm{~m}$ e 1 de $5,0 \times 2,0 \times 2,0 \mathrm{~m}$. Neste último viveiro foram colocados três casais ao mesmo tempo.

Os viveiros foram plantados com grama e possuíam um arbusto de "Ligustro" (Ligustrum sinensis), um de "Sangue de Adão" (Salvia splendens) e um de "Buxinho" (Buxus sempervirens). O viveiro maior não possuía arbustos e era plantado com touceiras de capim preto (Reineckia sp.).

Os materiais utilizados para a construção dos ninhos foram raízes de capim amargoso (Digitaria insularis) e fibras de sisal (Agave sisalana), fornecidos por mim, que os colocava nos viveiros na forma de pequenos maços.

A alimentação fornecida era constituída de alpiste, papa de pão com leite acrescida de chicória moída, gema de ovo e "Vitagold" (complexo vitamínico). Foram oferecidas também larvas de Tenebrio molitor.

\section{RESULTADOS}

As observações foram realizadas de setembro de 1972 a abril de 1977.

O período reprodutivo tem seus limites extremos entre agosto e junho, embora seja mais comum terminar em fins de maio.

\section{Territorialidade}

Durante a época reprodutiva, pode-se observar a defesa de território. No viveiro maior onde foram colocados três casais, houve construção de 2 ninhos ao mesmo tempo, por dois casais. As touceiras de capim preto onde foram construídos os ninhos distavam de $114 \mathrm{~cm}$. Podia-se notar a territorialidade dos cas̉ais sobre a região ao redor dos ninhos, o casal mais antigo no viveiro possuía maior agressividade em relação aos outros tisius e maior área de influência. A defesa de território é feita tanto pelo macho como pela fêmea, que procedem da seguinte forma: um dos dois se aproxima do intruso e emite um piado de agressão; o macho emite às vezes um canto, o qual deu origem ao seu nome onomatopáico, acompanhado de salto ou não. Quando o macho do casal vai afugentar um outro macho intruso, ele pousa próximo ao outro, abaixa as asas e mantém o corpo na horizontal, com o bico apontado para o outro, que se afasta imediatamente, ou adota a mesma postura e depois se afasta.

$\mathrm{O}$ salto realizado pelo macho, como mencionado acima, consiste em um pulo, acompanhado de bater de asas, que pode produzir um ruído ca- 
racterístico ou não, e da emissão do canto mencionado acima quando chega ao ápice de altura. Gira então o corpo para baixo, ficando a cauda por um instante erguida. Vêem-se perfeitamente as penas brancas do lado interno das asas durante o salto. A altura do salto varia conforme as circunstâncias.

\section{Comportamento nupcial}

A exibição de cortejamento consiste na adoção de uma postura na qual o macho fica com as asas semi-abaixadas, a cauda erguida, enquanto emite o mesmo canto já referido em territorialidade; às vezes salta emitindo este canto.

Mas o que mais freqüentemente se observa no relacionamento entre macho e fêmea é aquele voar para próximo da fêmea, acompanhando-a onde ela for e sendo ameaçado por ela, que ou abre o bico no sentido dele ou se projeta em direção a ele, provocando seu afastamento, seguido dali a pouco de nova perseguição. Quando ela está no chão, o macho voa sobre ela, podendo emitir um piado característico, aparentemente tentando pousar sobre as costas da fêmea, que costuma bicá-lo, provocando seu afastamento.

A fêmea possui uma postura de solicitação que é representada por um abaixamento das asas, que são tremuladas, e erguimento da cauda; ocorre também emissão de um piar característico.

A cópula se dá depois de o macho ter pairado sobre o dorso da fêmea. Pousa nas costas dela enquanto bate as asas rapidamente e abaixa a cauda por um dos flancos da fêmea. Ela ergue um pouco a cauda e emite um piado característico, com a cabeça erguida. Quando o macho se afasta ela treme as asas seguidas vezes. Podem ocorrer várias cópulas em seguida, com intervalos aproximados de $15 \mathrm{~min}$.

\section{Construção do Ninho}

$\mathrm{Na}$ construção do ninho em forma de taça, tomam parte tanto o macho como a fêmea, mas a participação do macho é mais ativa. Os ninhos observados foram construídos nos arbustos existentes nos viveiros como também nas touceiras de capim preto.

Nos casais observados por mim, inicialmente o macho voa por um arbusto, indo de forquilha em forquilha, às vezes arrancando com o bico alguns galhinhos secos destas forquilhas. Finalmente, segura uma raíz com o bico e a passa por uma forquilha do arbusto enroscando-a; depois vai prendendo outras raízes formando um círculo que será a borda do ninho.

Em continuação o macho ou a fêmea pousam no interior da taça semi-construída e com o bico vão pegando as pontas soltas de raízes e 
trançando-as com as outras já fixas. Às vezes trançam as raízes sem entrar no ninho, ficando pousados em um dos ramos que sustentam o ninho. Quando entram no ninho arrumam todas as raízes que estão por perto de seu bico. Estando o ninho quase terminado, podem forrá-lo ligeiramente com algumas poucas fibras de sisal.

Um dos casais estudados construiu um ninho diferente, tendo a forma de um tubo em $\mathrm{U}$, onde um dos braços era mais curto que o outro. Os dois orifícios das extremidades eram comunicantes através do tubo. A trama de raízes era frouxa, podendo ser visto o seu interior. Após 4 dias foi construído um fundo no braço mais longo, ficando assim fechada a comunicação entre as duas extremidades. Houve postura neste ninho, mas não ocorreu eclosão.

Os machos às vezes construíam um ninho novo enquanto o outro ninho ainda estava sendo usado, podendo também construir um ninho novo com o material de ninho que não estava mais sendo usado.

Os ninhos possuíam um diâmetro externo médio de $6,4 \mathrm{~cm}(\mathrm{n}=7)$, um diâmetro interno médio de $4,9 \mathrm{~cm}(\mathrm{n}=8)$ e uma profundidade média de $4,0 \mathrm{~cm}(\mathrm{n}=8)$, sendo menor diâmetro externo igual a $5,2 \mathrm{~cm}$, a maior igual a $7,5 \mathrm{~cm}$, o menor diâmetro interno de $4,6 \mathrm{~cm}$ e o maior de $5,4 \mathrm{~cm}$, a menor profundidade de $3,3 \mathrm{~cm}$ e a maior de $4,3 \mathrm{~cm}$.

A altura média acima do solo em que foi construído o ninho foi de $62 \mathrm{~cm}(\mathrm{n}=7)$, variando de $12 \mathrm{~cm}$ a $165 \mathrm{~cm}$.

\section{Ovipostura e incubação}

Houve duas oviposturas de um ovo cada, tendo ocorrido eclosão em apenas uma delas. Houve 16 oviposturas com 2 ovos, (Fig. 1) das quais seis não apresentavam eclosão, em três nasceram 1 filhote em cada, e nas nove restantes eclodiram todos. Dez oviposturas foram constituídas de 3 ovos, sendo que 1 ovipostura nasceu um filhote, em 5 nasceram 2 filhotes e em 4 eclodiram todos os ovos. Portanto a porcentagem de eclosão foi de $60,8 \%$.

Os ovos são brancos com pintas de cor castanho avermelhadas. Estas pintas podem se agrupar próximo ao polo mais largo, formando uma coroa.

O peso médio dos ovos é de $1,57 \mathrm{~g}(\mathrm{n}=2)$, o comprimento médio é de $1,77 \mathrm{~cm}(\mathrm{n}=5)$, e a largura média é de $1,35 \mathrm{~cm}(\mathrm{n}=5)$. Não houve medições de maior número de ovos pois a sua manipulação parecia acarretar a não eclosão.

O período médio de incubação foi de 11 dias $(n=10)$ sendo o mínimo de 10 dias e o máximo de 12 dias. Observei apenas a fêmea incubando (Tabela 1). 
Tabela 1

\begin{tabular}{|c|c|c|c|c|c|c|c|}
\hline Casal & Viveiro & $\begin{array}{c}\text { No de } \\
\text { posturas }\end{array}$ & Ninhos & $\begin{array}{l}\text { No ovos } \\
\text { por } \\
\text { postura }\end{array}$ & $\begin{array}{c}\text { Nọ eclosões } \\
\text { por } \\
\text { postura }\end{array}$ & $\begin{array}{c}\text { \% eclosão } \\
\text { por } \\
\text { postura }\end{array}$ & $\begin{array}{l}\text { tempo de } \\
\text { incubaçâo } \\
\text { (dias) }\end{array}$ \\
\hline \multirow{6}{*}{1} & \multirow{6}{*}{ D } & \multirow{6}{*}{6} & D1 & 2 & 2 & 100 & - \\
\hline & & & D2 & 3 & 2 & 66,6 & - \\
\hline & & & D3 & 2 & 0 & 0 & - \\
\hline & & & D4 & 2 & 0 & 0 & - \\
\hline & & & D5 & 2 & 2 & 100 & 10 \\
\hline & & & D6 & 2 & 2 & 100 & 10 \\
\hline \multirow{4}{*}{2} & \multirow{4}{*}{$\mathrm{F}$} & \multirow{4}{*}{4} & F1 & 2 & 2 & 100 & 10 \\
\hline & & & F2 & 2 & 2 & 100 & 10 \\
\hline & & & F3 & 1 & 0 & 0 & - \\
\hline & & & F4 & 3 & 3 & 100 & - \\
\hline 3 & G & 1 & G1 & 3 & 1 & 33,3 & 11 \\
\hline \multirow{14}{*}{4} & \multirow{14}{*}{$\mathrm{H}$} & \multirow{14}{*}{14} & $\mathrm{H} 1$ & 3 & 2 & 66,6 & - \\
\hline & & & $\mathrm{H} 2$ & 3 & 2 & 66,6 & 11 \\
\hline & & & $\mathrm{H} 2$ & 2 & 2 & 100 & 12 \\
\hline & & & H3 & 3 & 2 & 66,6 & - \\
\hline & & & H3 & 2 & 1 & 50 & - \\
\hline & & & H3 & 2 & 2 & 100 & - \\
\hline & & & H3 & 3 & 3 & 100 & - \\
\hline & & & $\mathrm{H} 3$ & 2 & 2 & 100 & - \\
\hline & & & $\mathrm{H} 3$ & 3 & 2 & 66,6 & 11 \\
\hline & & & $\mathrm{H} 3$ & 2 & 0 & 0 & - \\
\hline & & & $\mathrm{H} 3$ & 3 & 3 & 100 & - \\
\hline & & & H3 & 1 & 1 & 100 & - \\
\hline & & & $\mathrm{H} 4$ & 2 & 0 & 0 & - \\
\hline & & & $\mathrm{H} 4$ & 2 & 0 & 0 & - \\
\hline \multirow[t]{2}{*}{5} & \multirow[t]{2}{*}{$\mathrm{H}$} & \multirow[t]{2}{*}{2} & H'1 & 2 & 0 & 0 & - \\
\hline & & & H'1 & 2 & 1 & 50 & 11 \\
\hline 6 & $\mathrm{H}$ & 1 & H"1 & 3 & 3 & 100 & 10 \\
\hline
\end{tabular}

\section{Cuidados com a prole}

Tanto o macho como a fêmea alimentam os filhotes, quer durante o período de ninhego, como depois que deixam o ninho.

A alimentação colocada no viveiro durante o período de cuidados à prole era a mesma já mencionada anteriormente, acrescida de maior quantidade de larvas de Tenebrio molitor. Observei-os coletando artrópodos por entre o folhiço do solo e nas frinchas das paredes. Capturavam também insetos, como pequenas mariposas, no vôo.

As larvas de Tenebrio molitor antes de serem dadas aos filhotes, são amassadas com o bico pelos pais, ao longo de toda a sua extensão. Em seguida o macho ou a fêmea prendem-na no bico, próximo à cabeça $\mathrm{e}$ 
levam-na até um dos filhotes. Se o filhote ainda está no ninho, um dos pais pousa na borda do ninho e introduz a larva no interior da garganta de um dos filhotes, retira-a, expreme-a, regurgita. Repetem esta operação algumas vezes e por fim introduzem o exoesqueleto semi-vazio da larva na garganta do filhote. Às vezes revezam de filhote, introduzindo a larva ora na garganta de um, ora na garganta do outro. Quando a larva é pequena, o adulto a engole e depois a regurgita inteira na garganta do filhote.

Às vezes, quando a fêmea está chocando os ninhegos de poucas horas de nascidos, o macho, após se alimentar de larvas como o descrito, aproxima-se do ninho, tremula as asas semi-abertas, eriça as penas da coroa e emite um chamado característico. Outras vezes apenas emite o chamado e a fêmea sai de sobre os ninhegos e afasta-se emitindo um chamado diferente do produzido pelo macho. O macho pousa então na borda do ninho e'alimenta os ninhegos.

Os ninhegos são chocados tanto pela fêmea como pelo macho, mas por este só esporadicamente e durante poucos minutos.

Quando os adultos engolem o alimento que vai ser fornecido aos ninhegos ou filhotes, ficam com um saco gular bem evidente. Isto ocorre após a fase de desenvolvimento dos ninhegos, quando suas penas já estão quase livres das bainhas, com idade aproximada de 7 a 8 dias.

Observei a fêmea carregar no bico, para fora do ninho, sacos fecais dos ninhegos, quando estes tinham mais de 8 dias. Não observei nenhuma vez o macho nesta atividade. Também não foi possível observar se as fezes dos ninhegos mais novos são comidas ou não pelos pais.

Os ninhegos permanecem no ninho em média 9 dias $(n=9)$, sendo o mínimo de 8 dias e o máximo de 10 dias.

Quando saem do ninho, ainda não apresentam as penas completamente desenvolvidas. Costumam ficar pousados em locais escondidos, como os galhos internos dos arbustos existentes nos viveiros. Nesta época são alimentados pelos pais, que vão até eles. Os filhotes adotam a postura de pedir por alimento, que consiste em tremular as asas semiabertas, ao mesmo tempo emitem um piado, que, nos primeiros dias de saídos do ninho, é baixo, quase não dando para ser ouvido, e mantém o bico abduzido, quando um dos pais está muito próximo. $\mathrm{O}$ alimento é fornecido aos filhotes através de regurgitações seguidas; notei uma seqüência máxima de 7 regurgitações, sendo a média igual a 4 regurgitações seguidas. Na maioria das vezes, quando um dos pais está alimentando um dos filhotes, o outro adulto fica por perto agitando a cauda para os lados e emitindo chamados. Este comportamento é mais freqüênte quanto mais novos forem os filhotes.

Por volta do décimo dia fora do ninho, quando já se nota um maior controle do vôo por parte dos filhotes, eles mudam mais freqüentemente os locais de pouso, e em algumas ocasiões voam até um dos pais e pedem 
por alimento. Com o passar do tempo a procura dos pais por parte dos filhotes se torna mais freqüente e é cada vez mais raros os adultos irem até os filhotes e os alimentarem.

Parece que ocorre maior procura de insetos quando os filhotes são mais novos. Depois que deixam o ninho, a proporção de grãos dados aos filhotes aumenta, embora ainda sejam dadas larvas de Tenebrio molitor. Estas larvas são amassadas com o bico pelos pais, principalmente na região anterior, após o que são introduzidas inteiras com a extremidade anterior voltada para o interior da garganta dos filhotes.

Os filhotes, quando estão com a idade aproximada de 23 dias, ainda são alimentados pelos pais e pode-se notar que, em algumas ocasiões em que eles se aproximam de um dos adultos, adotando a postura de pedir por alimento, estes costumam bicá-los ou esticar o pescoço, estando o corpo horizontalmente disposto, abrir o bico e emitir um piar característico de agressão.

Quando um filhote está sendo alimentado, ou em vias de sê-lo, pia com uma freqüência maior do que quando está longe do casal.

Com idade ao redor de 30 dias são raramente alimentados pelos pais, só o sendo após voarem durante algum tempo atrás dos adultos pedindo por alimento. O macho praticamente não os alimenta mais, cabendo à fêmea alimentá-los esparsamente.

Por volta dos 36 dias de idade pedem por alimento, embora não sejam mais alimentados, e já se alimentem sozinhos, podendo ser considerados independentes.

Os filhotes machos só vão adquirir a plumagem adulta com a idade ao redor dos 6 meses.

\section{Variação da coloração do macho}

O macho adulto, durante o início de maio, sofre anualmente uma muda de penas que torna sua coloração, antes negra, brilhante, toda manchada de castanho metálico. Alguns indivíduos podem iniciar esta muda em meados de abril. Ficam com esta coloração de características crípticas até aproximadamente meados de setembro. Durante este período não ocorre reprodução, embora alguns machos possam iniciar a construção dos ninhos ainda com algumas manchas castanho-metálicas.

\section{DISCUSSÃO E CONCLUSÃO}

Com relação ao periodo reprodutivo, Goeldi (apud Carvalho, 1957) considera que esta subespécie nidifica em fevereiro, que está compreendido no período obtido por mim. Com relação à subespécie splendens, parece que procria praticamente o ano todo (Carvalho, 1957). 


\section{Territorialidade}

A territorialidade também foi observada em casais em condições naturais, durante o período reprodutivo. Ocorrem conflitos quando os limites dos territórios são ultrapassados (Alderton, 1963); Carvalho (1957); Alderton (1963) e Murray (1982) consideraram que o salto acompanhado de canto típico está relacionado com a territorialidade. Muitas espécies de aves usam do vôo para aumentar a eficiência de seus cantos de advertência.

O salto parece estar relacionado também com o cortejamento, como pude observar. Alderton (1963) sugere algum relacionamento entre salto e formação de casais.

\section{Construção do Ninho}

Como na subespécie estudada por mim, também em $V . j$. splendens a construção do ninho é realizada pelo casal, cabendo ao macho a iniciativa (Alderton, 1963).

O material utilizado na construção do ninho, na natureza, é constituído de talos de capim, radículas, raízes aéreas, fibras, caulículos secos, sendo internamente mais delicado (Euler, 1900 e Carvalho, 1957). Como se vê, o material fornecido e aceito pelos casais cativos não se diferenciou, quanto à qualidade, do material utilizado pela espécie em condições naturais.

As medidas do ninho, em forma de taça, dadas por Euler (1900), são de $7 \mathrm{~cm}$ de diâmetro e $3,5 \mathrm{~cm}$ de fundo, medidas externas. Carvalho (1957) dá as medidas internas como sendo 45 x 55 mm de diâmetro e 29 mm de profundidade. Para Alderton (1963) o ninho tem o diâmetro interno entre $45 \mathrm{~mm}$ e $51 \mathrm{~mm}$, o externo entre $45 \mathrm{~mm}$ a $90 \mathrm{~mm}$, a profundidade interna variando de 25 a $38 \mathrm{~mm}$ e a externa de 38 a $58 \mathrm{~mm}$. Peña (1981) encontrou para dois ninhos de $V$. J. jacarina, diâmetro de $5 \mathrm{~cm}$ e profundidade de $4 \mathrm{~cm}$. Portanto os dados obtidos por mim estão dentro das médias.

Para casais em liberdade, Carvalho (1957) encontrou um ninho a 25 $\mathrm{cm}$ do solo e Alderton (1963) considera as medidas extremas de 7,6 cm a $267 \mathrm{~cm}$. Portanto as medidas obtidas por mim, para pássaros em cativeiro, estão dentro do encontrado.

\section{Ovipostura e incubação}

A porcentagem de eclosão encontrada, de $60,8 \%$, pode ser considerada baixa levando-se em conta a porcentagem encontrada por Alderton (1963) que era de $73,5 \%$. 
Com relação ao número de ovos por ovipostura, Euler (1900) apresenta o valor 2. Von Ihering (1900) considera a ovipostura como sendo composta de 4 ovos. Peña (1981) encontrou dois ninhos de $V$. j. jacarina, na Argentina, um com 2 e o outro com 3 ovos. Carvalho (1957) e Alderton (1963) consideram, para a subespécie spledens, oviposturas de 2 a 3 ovos. Portanto o número de ovos por ovipostura encontrada por mim para $V . j$. jacarina não difere dos dados apresentados para a outra subespécie mencionada, e não foge dos dados encontrados na literatura para a subespécie em questão, a não ser com relação a aquele referido por Von Ihering.

Segundo Euler (1900) os ovos seriam "brancos, fortemente esverdeados, salpicados de manchas cor de vinho e bruno-vermelhas, que na extremidade posterior se reunem em cópula"'. Carvalho (1957) considera a cor de fundo como sendo branco puro. Já Alderton (1963) menciona a cor de fundo como sendo branca azulada, com manchas acastanhadas ou púrpureas ligeiramente concentradas no polo mais largo. A cor de fundo encontrada por mim para $V . j$. jacarina é branco puro, concordando com os dados obtidos por Carvalho para $V . j$. spledens. Com relação à cor das manchas, estão dentro das tonalidades esperadas considerando a subjetividade da nomenclatura utilizada para as diferentes tonalidades.

O peso dos ovos segundo Carvalho (1957) é de $1,6 \mathrm{~g}$, o que se assemelha à média obtida por mim. O tamanho dos ovos segundo Euler (1900) é de $16 \mathrm{~mm}$ de comprimento por 12,5 $\mathrm{mm}$ de largura. Von Ihering (1900) considera os ovos como medindo $18 \times 11,5-12,5 \mathrm{~mm}$. Carvalho (1957) cita a média encontrada por ele como sendo de $18,0 \times 13,0 \mathrm{~mm}$ (n = 19). Portanto o tamanho dos ovos estudados não difere consideravelmente dos citados na literatura.

Segundo Alderton (1963) o período de incubação varia de 10 a 12 dias; portanto, os dados obtidos para $V$. j. jacarina coincidem com aqueles de $V . j$. spledens. O mesmo autor cita o fato de a incubação ser realizada pelo casal, embora o macho incube esporadicamente por pouco tempo. Nos casais observados por mim, só notei a fêmea incubando.

\section{Cuidados com a prole}

Em condições naturais, tanto o macho como a fêmea de $V . j$. spledens alimentam os filhotes (Alderton, 1963). O mesmo se deu com os casais observados por mim. O casal de $V$. $j$. splendens alimenta os ninhegos com vermes, frutinhas e insetos que são levados à eles no bico (Alderton, 1963).

Com relação ao choco dos ninhegos, em casais de $V . j$. spledens em liberdade, tanto a fêmea como o macho chocam, embora o último o faça esporadicamente (Barnard, 1956 e Alderton, 1963), como ocorre em casais em cativeiro de $V . j$. jacarina. 
O saco gular já foi citado como ocorrendo em Carduelinae (Newton, 1967), sendo provavelmente, um meio de aumentar a capacidade de transporte de alimento até os filhotes. Aparece durante a estação reprodutiva em Leucosticte, Pinicola e Pyrrhula, quando estes pássaros alimentam os filhotes (Ffrench, 1954 e Newton, 1967).

Em $V . j$. spledens, em condições naturais, o bolo fecal dos ninhegos é comido pelos pais até o terceiro dia de vida. Do quarto dia em diante a fêmea passa a carregar as fezes para longe do ninho (Alderton, 1963). Só observei o carregar das fezes pela fêmea, não tendo notado se no início do desenvolvimento dos filhotes o casal comia as fezes.

Os ninhegos da subespécie splendens, na natureza, deixam o ninho com 9 dias (Barnard, 1956; Carvalho, 1957 e Alderton, 1963). O mesmo se deu com os pássaros em cativeiro, os filhotes de $V . j$. spledens em condições naturais também deixam o ninho com as penas ainda não totalmente desenvolvidas (Alderton, 1963).

\section{Variação da coloração do macho}

A coloração do macho com características crípticas é chamada por Sick.(1967) de plumagem de descanso.

$\mathrm{O}$ aparecimento de uma plumagem pro-críptica nos machos de algumas espécies de aves parece estar relacionado com a mortalidade mais alta destes em relação às fêmeas no período reprodutivo, devido a que a plumagem brilhante, selecionada devido à intensa competição por acasalamento, o torna, por outro lado, mais sujeito a predação (Lack, 1968).

\section{AGRADECIMENTOS}

À Fundação Parque Zoológico de São Paulo, na pessoa do seu saudoso Diretor Dr. Mario Autori, pelas instalações usadas para as observações em cativeiro. Ao Prof. Dr. Pierre Montouchet, pela revisão do Abstract.

\section{REFERÊNCIAS}

Alderton, C. C., 1963. The breeding behavior of the Blue-black Grassquit. Condor, $65: 154-162$.

Armstrong, E. A., 1965. Bird display and behaviour - An introduction to the study of bird psychology. New York, Dover, 431p.

Barnard, G. C., 1956. Nesting of the Blue-black Grassquit in Panamá. Condor, 58: 229231.

Carvalho, C. T. de, 1957. Notas ecológicas sobre Volatinia jacarina (Passeres, Fringillidae). Bol. Mus. Paraense "Emílio Goeldi", N. S., (2):1-10.

Euler, C., 1900. Descripção du ninhos e ovos das Aves do Brasil. Rev. Mus. paul., 4:9-148. 


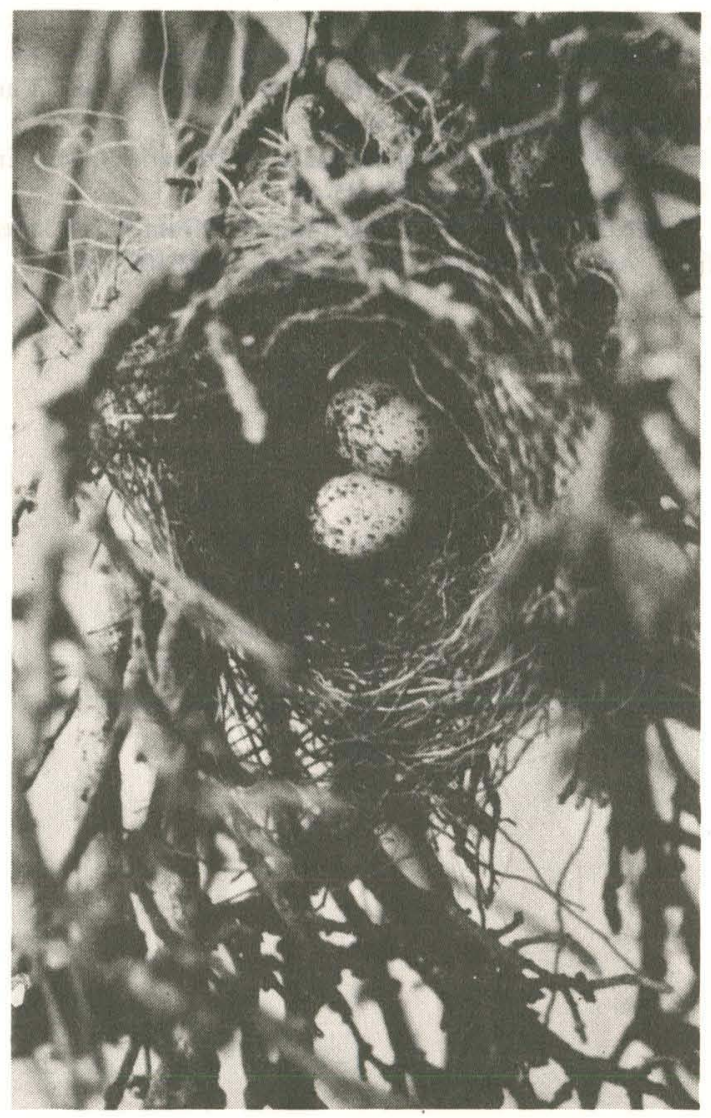

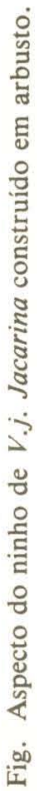


Ffrench, N. R., 1954. Notes on breeding activities and on gular sacs in the Pine Groesbeak. Condor, 56:83-85.

Lack, D., 1968. Ecological adaptations for breeding in birds. London Methuen, 409p. Marcondes-Machado, L. O., 1976. Alguns aspectos da biologia do comportamento reprodutivo de Volatinia jacarina jacarina (Aves, Emberizidae) em cativeiro. Ciênc. Cult., São Paulo, 28(7), sup. 903-904.

Murray, B. G., Jr., 1982. Territorial behavior of the Blue-Black Grassquit. Condor, 84:119.

Newton, I., 1967. The adaptative radiation and feeding ecology of some British finches. Ibis, 109:33-98.

Painter, Jr., R. A. \& Storer, R., 1970. Check list of birds of the World. Cambridge, Mass., USA, Mus. Comp. Zool., V. 13, 443p.

Peña, M. R. De La, 1981. Notas nidobiológicas sobre corbatias (Aves, Emberizidae). Segunda Parte. História Natural, 2(6):45-48.

Sick, H., 1967. "Bico de Ferro" - Overlooked seadeater from Rio de Janeiro (Sporophila, Fringiilidae, Aves). Anais Acad. bras. Ciênc., 39(2):307-314. 